\title{
Intervenção com modelos didáticos no processo de ensino-aprendiza- gem do desenvolvimento embrionário humanọ: uma contribuição para a formação de licenciados em ciências biológicas
}

Intervention with teaching models in teaching-learning process about the human embryonic development: a contribution to the training of graduates in biological sciences

Míriam dos Santos Meira*1, Leonan Guerra², Cristiane Köhler Carpilovsky³, Raquel Ruppenthal ${ }^{4}$, Kélen de Barcelos Astarita ${ }^{5}$ e Maria Rosa Chitolina Schetinger ${ }^{6}$

\author{
${ }^{1}$ Doutoranda, Docente do Departamento de Morfologia - Universidade Federal de Santa Maria, Brasil. \\ ${ }^{2}$ Mestrando do Curso de Pós-Graduação Educação em Ciências: Química da Vida e Saúde - Universidade Federal de Santa \\ Maria, Brasil. \\ ${ }^{3}$ Docente do Departamento de Morfologia - área de Histologia e Embriologia - Universidade Federal de Santa Maria, Brasil. \\ ${ }^{4}$ Doutoranda do Curso de Pós-Graduação Educação em Ciências: Química da Vida e Saúde - Universidade Federal de Santa \\ Maria, Brasil. \\ ${ }^{5}$ Acadêmica do Curso de Graduação em Enfermagem - Universidade Federal de Santa Maria, Brasil. \\ ${ }^{6}$ Docente do Departamento de Bioquímica e Biologia Molecular e do Curso de Pós - Graduação Educação em Ciências: Química \\ da Vida e Saúde - Universidade Federal de Santa Maria, Brasil.
}

\begin{abstract}
Resumo
O presente trabalho consiste na análise do potencial pedagógico de modelos didáticos tridimensionais, que foram utilizados em aulas de Embriologia Humana, junto a graduandos em Ciências Biológicas da Universidade Federal de Santa Maria (UFSM), RS. Tal intervenção foi realizada após aulas teóricas e de microscopia referentes à embriogênese humana inicial. Para a coleta de dados, um teste ilustrado, com questões fechadas e semiestruturadas, foi aplicado em três momentos distintos: antes das aulas de Embriologia Humana (pré-teste), após as aulas teóricas e de microscopia (teste pós-teoria) e após aulas com os modelos embriológicos (teste pós-intervenção). Os dados obtidos foram analisados de forma qualitativa e quantitativa. Tal análise demonstrou que o desempenho da amostra no teste pós-intervenção foi consideravelmente maior do que nas aplicações anteriores. Considera-se, portanto, que a intervenção com os modelos contribuiu, de forma significativa, para o processo de ensino-aprendizagem referente ao desenvolvimento embrionário humano, possibilitando assim, que a amostra obtivesse uma maior apropriação desse conhecimento. Nesse sentido, destaca-se a importância da construção elou utilização de tais recursos na formação inicial e continuada de professores da área, para que tais ferramentas venham a ser, efetivamente, utilizadas nos diferentes níveis do ensino de Ciências.
\end{abstract}

Palavras-chave: Modelos didáticos. Embriologia humana. Ensino. Aprendizagem

\begin{abstract}
This research consists in analyzing the pedagogical potential of three-dimensional teaching models, which were used in lessons of Human Embryology with a class of graduate students in Biological Sciences at Federal University of Santa Maria (UFSM), RS. Such intervention was conducted after theoretical and microscopy's classes related to early human embryogenesis. For data collection, an illustrated test with closed and semi-structured questions was applied at three different times: before classes of Human Embryology (pretest), after the theoretical and microscopy's classes (post-theory test) and after classes with embryological models (post-intervention test). The data were analyzed qualitatively and quantitatively. This analysis showed that the sample performance in post-intervention test was considerably higher than in earlier applications. It is considered therefore that the intervention using models contributed significantly to the process of teaching and learning related to human embryonic development, which contributed to the sample to obtain a better appropriation of that knowledge. In this sense, it is remarkable the importance of building and/or using such resources in initial and continuing teacher training, to allow such tools to be effectively used in different levels of teaching of science.
\end{abstract}

Keywords: Teaching models. Human embryology. Teaching. Learning

Recebido: 16/10/2014 Aceito:07/01/2015

*miriameira@gmail.com 


\section{Introdução}

A fim de favorecer a aprendizagem nas diferentes áreas do conhecimento, cabe ao professor, em qualquer nível de ensino, buscar a diversificação de metodologias e de recursos didáticos, evitando realizar, exclusivamente, aulas do estilo "tradicional", entendidas aqui como aulas teóricas expositivas não dialogadas, ilustradas ou não, em que o aprendiz é colocado (e geralmente se mantém) em uma postura totalmente passiva. No que se refere ao ensino de Ciências (Biologia, Química e Física), a ocorrência de aulas práticas ou teórico-práticas é fundamental para a compreensão dos processos e apropriação de conceitos. Especificamente com relação às Ciências Biológicas, Pedrancini et al. (2007, p. 305) destacam:

Os principais motivos que dificultam a aprendizagem significativa de conceitos e processos biológicos residem no ensino fragmentado e conservador, a reboco da ciência do século XIX, restringindo o aluno a cumprir tarefas repetitivas, sem sentido ou significado, valorizando somente a reprodução do conhecimento e, consequentemente, formando apenas repetidores.

Segundo Nascimento et al. (2012), as práticas metodológicas que favorecem a aprendizagem podem levar ao entendimento e à assimilação de conteúdos que por envolverem, por exemplo, a dimensão microscópica, são de difícil compreensão. Os conteúdos de Embriologia Humana justamente envolvem tal dimensão, além de demandarem conhecimentos prévios referentes, por exemplo, à divisão e diferenciação celulares. Para Yamada et al. (2006), as mudanças morfogenéticas que caracterizam o desenvolvimento pré-natal humano são complexas e, portanto, a compreensão de sua dinâmica requer a visualização das estruturas embrionárias em, pelo menos, três dimensões (3D).

Considerando o exposto, os modelos didáticos tridimensionais podem atuar como importantes ferramentas facilitadoras do processo de ensino e aprendizagem acerca do desenvolvimento embrionário humano (ASSMANN et al., 2004; FREITAS et al., 2008; OLIVEIRA et al., 2012; AVERSI-FERREIRA et al., 2012). A exemplo de Oliveira et al. (2012), através desta pesquisa, pretende-se promover um aprendizagem efetiva, além de contribuir para a diversificação das formas de estudo. Nesse sentido, constituíram objetivos específicos:

- produzir modelos tridimensionais e utilizá-los, de forma interventiva, em aulas de Embriologia Humana;

- analisar a validade do uso de tais ferramentas pedagógicas no processo de ensino-aprendizagem;

- contribuir para a formação na área de Ciências Biológicas.

\subsection{Importância da Embriologia Humana}

Através de toda a história da humanidade, as diferentes populações sempre tiveram interesse em saber como foram originadas, como se desenvolveram, como nasceram e por que motivo alguns indivíduos apresentam um desenvolvimento anormal (GILBERT, 1995; MOORE; PERSAUD, 2000). Atualmente, esse interesse continua sendo muito grande, não só em função da curiosidade sobre a própria formação, mas também pelo objetivo de melhorar a qualidade da vida humana (MOORE; PERSAUD, 2004, 2008).

A importância da Embriologia está, portanto, em explicar a origem da estrutura humana normal e das malformações congênitas (MOORE et al., 2013). Por isso, tal estudo é essencial para os cursos de graduação das áreas das ciências da saúde e das ciências naturais. A Embriologia Humana, geralmente associada à Biologia Estrutural dos Tecidos (Histologia), constitui uma disciplina básica para tais cursos, facilitando o estudo da Histologia, da Anatomia e da Fisiologia e complementando conteúdos da Biologia Molecular e da Genética, por exemplo.

O objeto de estudo da Embriologia Humana é a etapa pré-natal do desenvolvimento, que vai desde a formação do zigoto até o nascimento. O zigoto é uma célula altamente especializada e totipotente que, através de vários processos - multiplicação, crescimento, diferenciação e rearranjo celulares - transforma-se em um organismo multicelular (MOORE et al., 2013). Devido à complexidade de tal transformação, compreender o desenvolvimento embrionário não é uma tarefa fácil. Segundo OLIVEIRA et al. (2012, p. 84), “... o estudo de determinados conteúdos embriológicos é árduo, desestimulante, pouco prazeroso e, muitas vezes, nada efetivo."

Considerando o exposto, o processo de ensino-aprendizagem nessa área deve incluir recursos metodológicos capazes de possibilitarem as várias interpretações espaciais que, segundo Rodrigues et al. (2004), são necessárias para que o aprendiz compreenda os processos embriológicos. Dentre as alternativas didáticas capazes de ir além da bidimensionalidade dos livros-texto, facilitando assim tal compreensão, podemos citar, por exemplo: os vídeos, as animações, a produção e a utilização de modelos didáticos tridimensionais.

\subsection{Modelos e Modelização}

A elaboração e utilização de modelos são recursos didáticos muito utilizados nos diferentes níveis do Ensino de Ciências. Segundo Guimarães; Ferreira (2006), a produção de modelos pode dar ao professor um grande aporte pedagógico para trabalhar no ensino de Ciências. Westphal; Pinheiro (2004), relacionando modelização e realismo científico, também defendem que para o desenvolvimento do ensino nesta área, há necessidade da construção de imagens "verdadeiras" da realidade (modelos).

Diversos tipos de modelos são descritos na literatura. Gilbert (2004) aborda, entre outros, os modelos (1) mentais, que seriam representações pessoais, que 
um indivíduo constrói isolado ou em grupo, mas que só se tornam acessíveis aos demais se forem expostas; (2) científicos, que seriam modelos que se tornaram consensuais para um grupo de cientistas; e (3) os didáticos ou de ensino, que seriam aqueles construídos com objetivo exclusivamente educacional, para dar suporte ao processo de ensino e aprendizagem, facilitando a transformação de um conhecimento científico em um conhecimento curricular.

Segundo Justi; Van Driel (2006), os modelos de ensino podem ter vários modos de representação: analogias, simulações, desenhos e modelos concretos.

Os modelos concretos são tridimensionais e construídos com materiais resistentes (GILBERT, 2004). Auxiliam nas interpretações espaciais essenciais à compreensão da morfologia humana (PEROTTA et al., 2004) e, por isso, constituem o tipo de modelo utilizado neste trabalho. Podem ser maiores ou menores do que os objetos que representam (GILBERT, 2004). No caso dos modelos embriológicos, as dimensões são, logicamente, muito maiores do que as de um embrião real, visto que com duas semanas, por exemplo, segundo Moore et al. (2013), um embrião humano apresenta cerca de $1 \mathrm{~mm}$ somente.

Tais ferramentas despertam a curiosidade (OLIVEIRA et al., 2012) e sua construção estimula a criatividade do aluno, além de favorecer a interatividade e as relações interpessoais, uma vez que tais atividades geralmente são realizadas em grupos. A construção e/ou o uso de modelos tridimensionais oportuniza aulas dinâmicas e interativas, em que o aluno não figura como mero e passivo expectador e sim como agente ativo no processo de ensino-aprendizagem. Além disso, a construção e/ou o uso de modelos didáticos pode ser feita sem a necessidade de materiais de alto custo (FREITAS et al., 2008) e de equipamentos eletrônicos, multimídia e acesso a web sites.

No que se refere a aulas e projetos de ensino e, inclusive, de extensão referentes às Ciências Biológicas, a construção e/ou análise de modelos didáticos têm sido utilizada. Vários são os exemplos dessa utilização nos diferentes campos do conhecimento: em Biologia Celular (SEPEL; LORETO, 2003); em Genética (JUSTINA; FERLA, 2006; SEPEL; LORETO, 2007; SETÚVAL; BEJARANO, 2009; TEMP et al., 2011); em Neurofisiologia (AVERSIFERREIRA et al., 2008); em Zoologia (NASCIMENTO et al., 2012); em Química (SOUSA et al., 2013), em Histologia (MEIRA, 2013) e relacionados ao tema desta pesquisa: Reprodução e Embriologia (ASSMANN et al., 2004); Fases da embriogênese (FREITAS et al., 2008; AVERSI-FERREIRA et al., 2012) e Embriologia do Sistema Nervoso (OLIVEIRA et al., 2012).

Avanços tecnológicos recentes têm possibilitado a obtenção de imagens em 3D (tridimensionais) e 4D (tridimensionais em movimento) das transformações que ocorrem, in utero, com embriões e fetos humanos (SHIOTA, 2012). É lógico que o potencial didático de tais recursos é inquestionável, porém consideramos que tal estudo pode ser extra-classe. Preferimos oportunizar, em sala de aula, o uso de ferramentas palpáveis (reais) e não eletrônicas (virtuais) também porque, com maior frequência, temos ministrado aulas para acadêmicos com deficiências visuais, pois os modelos tridimensionais possibilitam as experiências sensoriais imprescindíveis para os alunos com tais necessidades especiais, apresentando, portanto, um caráter inclusivo (RIBEIRO, 2004). Tais recursos, segundo Freitas et al. (2008, p.95) “... permitem ao discente formar imagens mais próximas das estruturas dinâmicas reais que se sucedem no período de desenvolvimento ontogênico dos mamíferos..."

\section{Materiais e Métodos}

Este estudo faz parte de um projeto de pesquisa, em nível de doutorado, da primeira autora. Foi aprovado pelo Comitê de Ética em Pesquisa da UFSM, com Certificado de Apresentação para Apreciação Ética (CAAE) nº 0152.0.243.000-11. Caracteriza-se como descritivo (GIL, 2006), abordando aspectos qualitativos e quantitativos.

\section{a) Composição da amostra}

A amostra foi composta por 20 acadêmicos do curso de graduação em Ciências Biológicas da UFSM, que ingressaram em 2012. Constituíram critérios de inclusão: estar ingressando no referido curso, ainda não ter cursado a disciplina de Embriologia em outro curso de graduação e assinar o Termo de Consentimento Livre e Esclarecido - TCLE. Todos participaram de forma voluntária e, após assinarem o TCLE, receberam o Termo de Confidencialidade.

\section{b) Elaboração do teste de conhecimento}

As questões do teste (anexo 1) foram elaboradas e ilustradas a partir de literatura especializada em Embriologia Humana e, principalmente, a partir de livros de Biologia: Amabis; Martho (1997), Lopes (2006) e os indicados pelo Plano Nacional do Livro para o Ensino Médio (PNLEM) de 2009 (BRASIL, 2008), uma vez que a maior parte da amostra cursou o Ensino Médio de 2009 a 2011. O teste constou de 8 questões, sendo 6 fechadas e 2 semiestruturadas. Antes de ser aplicado, tal instrumento foi validado por uma comissão de pesquisadores da área de Educação em Ciências.

Todas as questões apresentavam ilustrações referentes a processos ou estruturas observáveis nos embriões humanos nas quatro primeiras semanas de vida intra-uterina. As questões fechadas eram de múltipla escolha, com 4 alternativas cada uma (a, b, c, d). Das questões semiestruturadas, uma indicava com setas as estruturas a serem identificadas na figura, enquanto a outra apresentava estágios da embriogênese, solicitando a enumeração dos mesmos conforme a sequência em que ocorrem no sistema reprodutor feminino. 


\section{c) Construção dos modelos didáticos}

Para a construção dos modelos embriológicos tridimensionais foram utilizadas como base as figuras apresentadas em Moore; Persaud (2008). Os referidos modelos foram confeccionados pelo segundo autor deste artigo, conforme descrição a seguir.

O processo iniciou com a homogeneização de sabonete ralado, cola e polvilho doce até obter uma mistura consistente e plástica chamada porcelana fria. Logo após, essa mistura foi tingida de várias cores e moldada em diversas estruturas. Através da associação de argila hidratada (peneirada para retirada de todas as impurezas), foram produzidos modelos com ótima resistência. Em uma semana os modelos estavam secos e prontos para serem lixados e pintados.

Apenas as partes moldadas com argila hidratada foram lixadas com lixa específica para madeira. Em seguida, as partes de argila foram pintadas com tinta acrílica específica para artesanato e impermeabilizadas com verniz, também próprio para artesanato. Logo após, quando necessário, foram fixadas às estruturas de porcelana fria que já estavam tingidas com as cores específicas de cada estrutura. Os modelos foram confeccionados e padronizados em cores específicas para as estruturas internas e externas representativas dos estágios iniciais do desenvolvimento embrionário humano.

Cabe destacar que, apesar de os modelos terem sido meticulosamente produzidos, devido a dificuldades inerentes ao processo de modelagem, pequenas diferenças de proporção são observadas em relação às figuras de Moore; Persaud (2008).

As figuras 1 a 6 apresentam as fotos dos modelos com o diâmetro ou o comprimento maior de cada um.

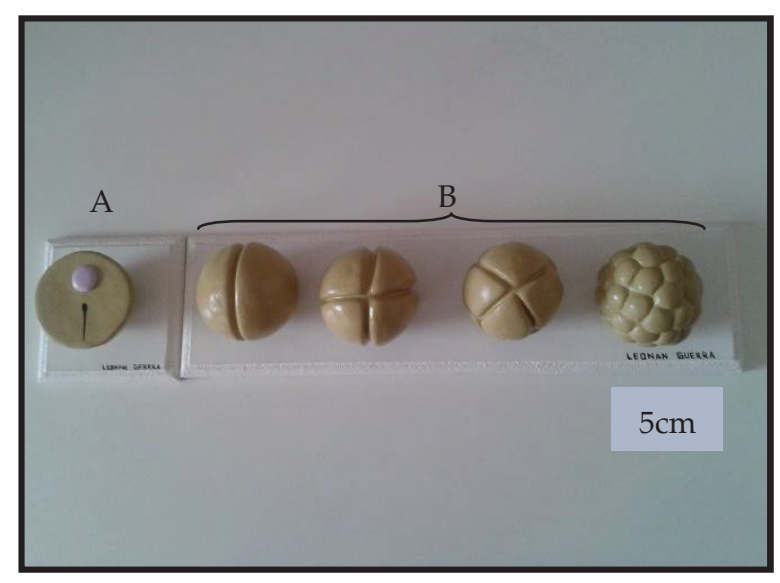

Figura 1 - Modelos representativos da fertilização (A) e da clivagem (B). Tamanho real nas fases representadas: 0,04mm (DEPARTAMENTO DE MORFOLOGIA DA UNIFESP)

\section{d) $1^{\mathbf{a}}$ aplicação do teste de conhecimentos}

Foi realizada no primeiro semestre de 2012, ocasião em que os graduandos amostrados estavam ingressando no Curso de graduação em Ciências Biológicas da UFSM,

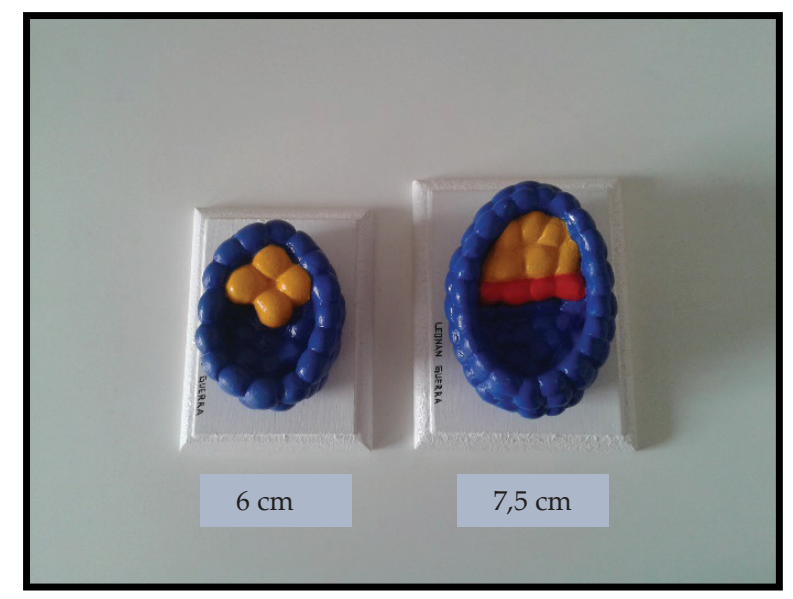

Figura 2 - Modelos representativos da blastogênese. Em A, blastocisto com cerca de 6 dias; em B, com cerca de 7 dias. O tamanho real é de aproximadamente 0,05mm (A) e 0,07mm (B) (estimados a partir de MOORE; PERSAUD, 2008)

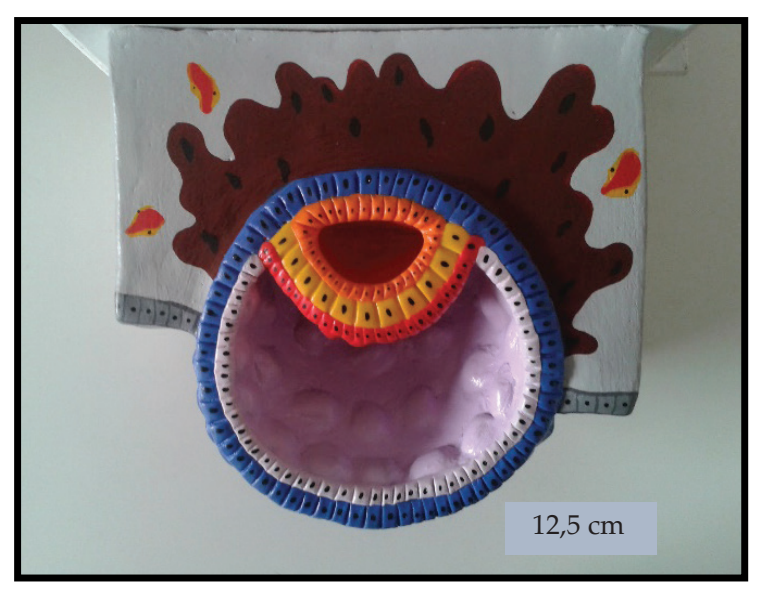

Figura 3 - Modelo representativo da implantação do blastocisto no útero (cerca de 8 dias). Tamanho real do concepto (embrião associado a seus anexos extraembrionários): 0,1mm (MOORE; PERSAUD, 2008)

Tal aplicação foi denominada de pré-teste ou teste 1 (T1).

\section{e) $2^{a}$ aplicação do teste de conhecimentos}

A exemplo de Ajaja (2013), foi aguardado o período de duas semanas após as aulas (teóricas e de microscopia) para realizar nova aplicação do teste de conhecimentos. Tal aplicação foi denominada então, de teste pós-teoria ou teste 2 (T2).

\section{f) $3^{\mathbf{a}}$ aplicação do teste de conhecimentos}

Esta última aplicação do teste de conhecimentos foi realizada uma semana após a intervenção com os modelos. Tal aplicação foi denominada teste pós-intervenção ou teste 3 (T3). 


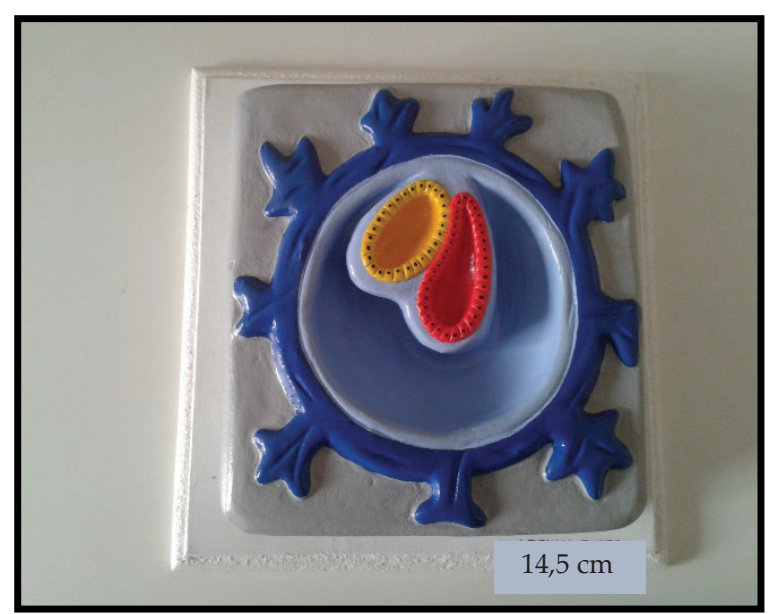

Figura 4 - Modelo representativo de concepto com cerca de 14 dias. Tamanho real: aproximadamente $1 \mathrm{~mm}$ (MOORE; PERSAUD, 2008)

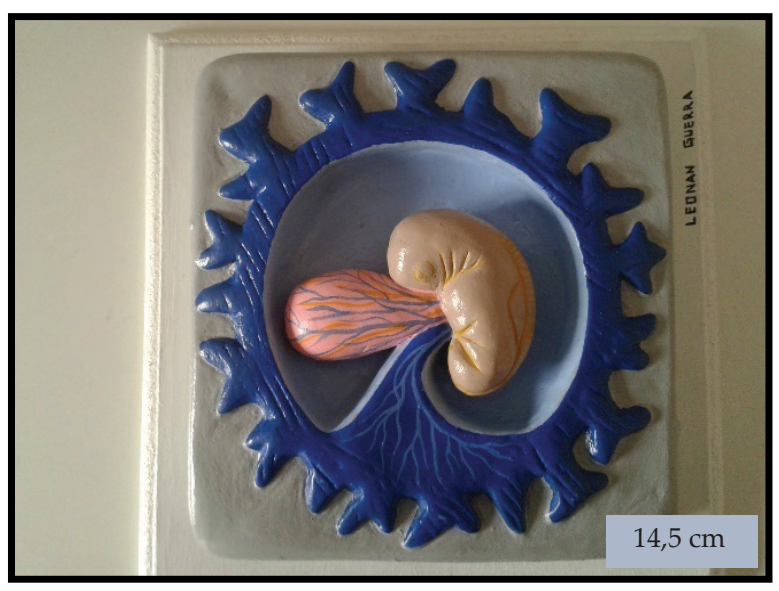

Figura 5 - Modelo representativo de concepto com cerca de 26 dias. Tamanho real: aproximadamente $4 \mathrm{~mm}$ (MOORE; PERSAUD, 2008)

Cabe destacar que todas as aulas, incluindo a intervenção, foram conduzidas pela primeira autora. Porém, a aplicação dos testes foi realizada por outros professores ou por monitores do Departamento de Morfologia/UFSM.

\section{g) A intervenção}

Consistiu em uma aula teórico-prática, constituída por duas etapas de $1 \mathrm{~h}$ e 20 minutos, intercaladas por intervalo de 20 minutos, totalizando portanto, cerca de 3 h. Para tal atividade, os alunos se organizaram em grupos de 5 componentes e receberam um roteiro (quadro 1) e bibliografia especializada em Embriologia Humana (SADLER, 1995; 2005; MOORE; PERSAUD, 2008; ROHEN; LÜTJEN-DRECOLL, 2005) para auxiliar na identificação dos processos e estruturas representados pelos modelos. Desta forma, os graduandos tiveram a oportunidade de analisar e manusear os modelos, além de fazer uma representação esquemática (desenho) dos mesmos.

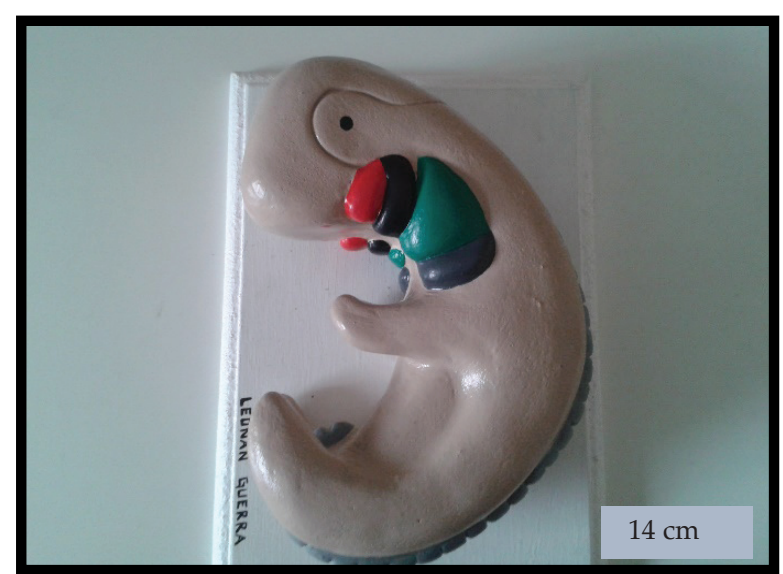

Figura 6 - Modelo representativo de embrião com cerca de 28 dias. Tamanho real: aproximadamente $4,5 \mathrm{~mm}$ (MOORE; PERSAUD, 2008)

Dos conteúdos apresentados na tabela 1, foram contemplados pelos modelos (aula do tipo 3): a fertilização, as principais estruturas e fases características da primeira, segunda e quarta semanas de vida intra-uterina e, ainda, a constituição e aspectos funcionais da placenta e do cordão umbilical. Destaca-se que a terceira semana de desenvolvimento, apesar de ter grande importância, não foi representada pelos modelos porque a complexidade dos eventos e estruturas dessa fase dificultaria a produção dos mesmos.

Quadro 1 - Roteiro proposto para a aula teóricoprática (intervenção) com os modelos didáticos.

1-Represente esquematicamente os modelos apresentados, indicando nos desenhos as estruturas visíveis nos modelos que representam:

a) a fertilização e a clivagem

b) os blastocistos inicial e tardio

c) o embrião parcialmente implantado

d) o concepto ao final da $2^{\underline{a}}$ semana

e) o embrião ao final da $4^{\underline{a}}$ semana

f) o concepto ao final da $4^{\underline{a}}$ semana

\section{h) Análise dos dados}

Constou de tratamento estatístico, através de cálculos de frequência simples e média (TRIVIÑOS, 2008) seguidos pela elaboração de gráficos e tabelas para análise comparativa das respostas obtidas nas três aplicações (T1, T2 e T3). Para comparar tais resultados, foram utilizadas as frequências de questões corretas (CO), incorretas (IN) e não respondidas (NR), acrescentando-se a categoria parcialmente corretas (PC) para as questões 
semiestruturadas.

Tabela 1- Desenvolvimento das aulas de Embriologia Humana.

\begin{tabular}{|c|c|c|}
\hline $\begin{array}{l}\text { Conteúdos } \\
\text { ministrados }\end{array}$ & $\begin{array}{l}\text { Tipo de } \\
\text { aula }\end{array}$ & h/aula \\
\hline $\begin{array}{l}\text { Gametogênese } \\
\text { feminina e masculina }\end{array}$ & 1,2 & $4^{*}$ \\
\hline $\begin{array}{l}\text { Ciclos ovariano e } \\
\text { endometrial }\end{array}$ & 1 & 2 \\
\hline $\begin{array}{c}\text { Fecundação e } \\
\text { primeira semana de } \\
\text { gestação }\end{array}$ & 1,3 & 3 \\
\hline $\begin{array}{l}\text { Segunda semana de } \\
\text { gestação }\end{array}$ & 1,3 & 3 \\
\hline $\begin{array}{l}\text { Terceira semana de } \\
\text { gestação }\end{array}$ & 1 & 5 \\
\hline $\begin{array}{c}\text { Quarta à oitava } \\
\text { semana de gestação }\end{array}$ & 1,3 & 4 \\
\hline Gravidez múltipla & 1 & 2 \\
\hline $\begin{array}{l}\text { Placenta e anexos } \\
\text { embrionários }\end{array}$ & $1,2,3$ & $4^{*}$ \\
\hline \multirow[t]{2}{*}{$\begin{array}{l}\text { Malformações } \\
\text { congênitas }\end{array}$} & 1 & 3 \\
\hline & TOTAL & $30 \mathrm{~h} / \mathrm{a}$ \\
\hline
\end{tabular}

* 2 teóricas e 2 práticas.

1. Aulas teóricas: aulas expositivas, dialogadas e ilustradas com recursos multimídia. "Dialogadas" porque a professora (primeira autora deste trabalho) procurou questionar os alunos ao expor cada item do conteúdo, ou seja, procurou utilizar o conhecimento prévio dos acadêmicos na sequência dos itens a serem explicados. E "ilustradas" porque incluíram a apresentação de uma série de figuras através de projetor multimídia (data-show).

2. Aulas práticas: com análise microscópica de lâminas com secções de ovário, testículo, placenta e cordão umbilical.

3. Aula teórico-prática: intervenção descrita no item $\mathrm{f}$.

\section{Resultados e Discussão}

O resultado das questões fechadas, obtido nas três aplicações do teste de conhecimentos, está apresentado nas figuras 7 a 9 .

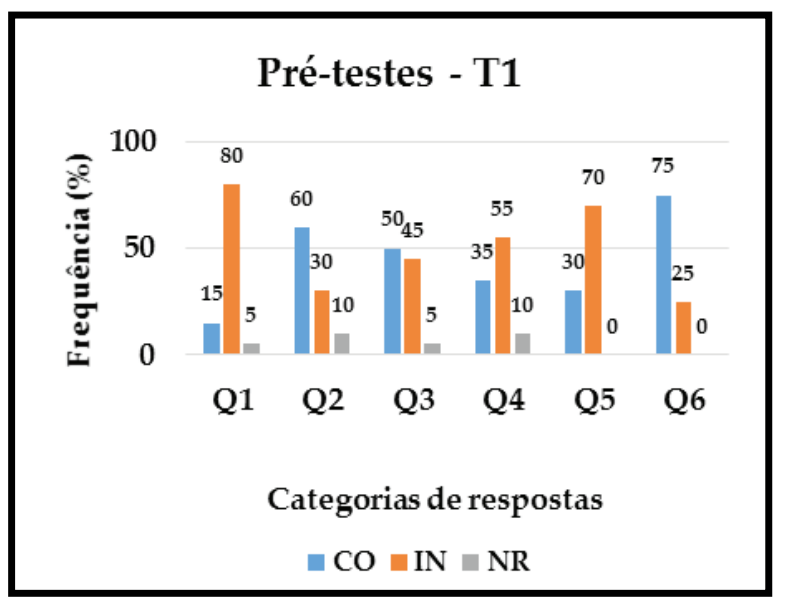

Figura 7 - Distribuição da amostra de acordo com as categorias de respostas obtidas para as 6 questões fechadas (Q1 a Q6), no pré-teste $(\mathrm{T} 1)$, onde $\mathrm{CO}=$ corretas; $\mathrm{IN}=$ incorretas; NR = não respondidas.

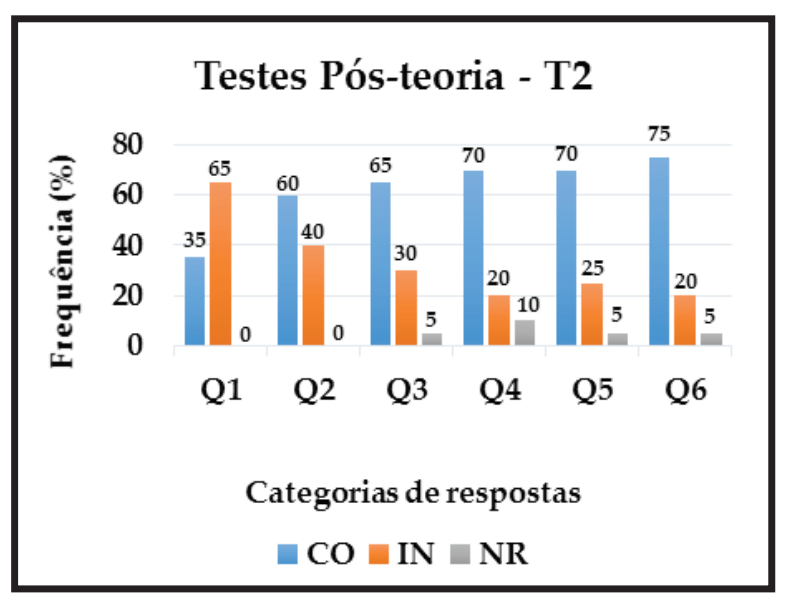

Figura 8 - Distribuição da amostra de acordo com as categorias de respostas obtidas para as 6 questões fechadas (Q1 a Q6), no teste pós-teoria (T2), onde $\mathrm{CO}=$ corretas; IN = incorretas; $\mathrm{NR}=$ não respondidas.

Como pode ser observado na figura 7 , referente aos pré-testes, três questões (Q2, Q3 e Q6) tiveram frequência de acertos (CO) variando entre $50 \%$ e $75 \%$, enquanto as outras três (Q1, Q4 e Q5) tiveram de 55 a $80 \%$ a frequência de respostas incorretas (IN).

Comparando a figura $7 \mathrm{com}$ a 8 , referente aos testes pós-teoria (T2), com exceção de Q2, todas as questões tiveram redução na frequência de respostas incorretas (IN) e, com exceção de Q6, todas as questões tiveram maior frequência (60 a 75\%) de respostas corretas (CO).

Conforme figura 9 , referente aos testes pós-intervenção (T3), com exceção de Q1, que teve a mesma frequência de erros e acertos, todas as questões apresentaram a frequência de acertos entre 80 e $85 \%$. 


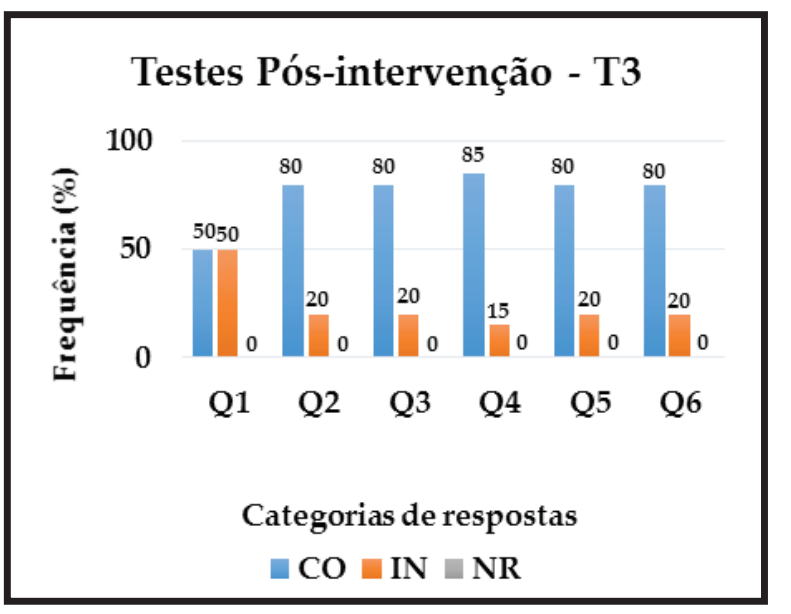

Figura 9 - Distribuição da amostra de acordo com as categorias de respostas obtidas para as 6 questões fechadas (Q1 a Q6), no teste pós-intervenção (T3), onde $\mathrm{CO}=$ corretas; $\mathrm{IN}$ = incorretas; $\mathrm{NR}=$ não respondidas.

Além disso, a maioria das questões tiveram a categoria não respondidas (NR) representada com uma frequência de 5 a 10\% nos T1 e T2, enquanto no T3 todos os alunos responderam a todas as questões (Q1 a Q6). Portanto, a frequência de NR diminuiu ao longo das três aplicações do teste, reduzindo para zero no T3.

No que se refere aos conteúdos enfocados, discutimos, a seguir, as questões fechadas.

As questões 1 e 2 (Q1 e Q2) eram referentes à fase de segmentação ou clivagem, ou seja, às primeiras divisões que ocorrem após a fertilização (MOORE et al., 2013), e que foram representadas na intervenção pelos modelos da figura 1. Apesar de tratarem do mesmo assunto, tais questões tiveram resultados muito diferentes nas três aplicações, principalmente no T1 (Q1 com poucos e Q2 com muitos acertos), evidenciando que a maioria da amostra não conseguiu relacionar, corretamente, as duas questões.

A questão 3 (Q3) era referente à estrutura do embrião com 8 dias e ao início da circulação materno-embrionária, enquanto a questão $4(\mathrm{Q} 4)$ referia-se à implantação do blastocisto no útero. Tais estruturas e processos foram representados pelos modelos das figuras 2 e 3 . A progressão na frequência de acertos, de T1 para T3, ocorreram para Q3 e Q4, sendo que no T3 tal frequência atingiu 80 e $85 \%$, respectivamente. Portanto, pode-se considerar que os modelos das figuras 2 e 3 cumpriram muito bem a sua função ilustrativa, complementando ou elucidando as aulas teóricas e leituras dos alunos referentes a tais assuntos.

As questões 5 e 6 (Q5 e Q6) eram referentes à placenta, ao cordão umbilical e à importância destas estruturas no desenvolvimento embrionário e fetal. Tais estruturas foram representadas nos modelos das figuras 4 e 5 . No que se refere ao T1, os resultados obtidos para Q5 e Q6 foram muito diferentes, pois 70\% das respostas foram incorretas (IN) no caso de Q5, enquanto 75\% das respostas foram corretas (CO) em se tratando de Q6. Porém, os resultados obtidos para tais questões foram muito próximos em T2 (70 e 75\%, respectivamente) e exatamente iguais em T3 (80\%).

A frequência de acertos igual ou superior a $70 \%$, obtidas desde o pré-teste (para Q6) e a partir do T2 para ambas as questões, pode ser atribuída ao fato de que aspectos morfológicos e funcionais da placenta e do cordão umbilical são apresentados na grande maioria dos livros de Biologia. Além disso, noções referentes a esses aspectos fazem parte do senso comum, inclusive indivíduos com baixo nível de escolaridade apresentam tais percepções.

O resultado das questões semiestruturadas, obtido nas três aplicações do teste de conhecimentos, está apresentado nas figuras 10 a 12. Conforme tais figuras, do T1 para T3 diminuiu, significativamente, a frequência de questões NR, aumentando as PC (Q7) ou as CO (Q8).

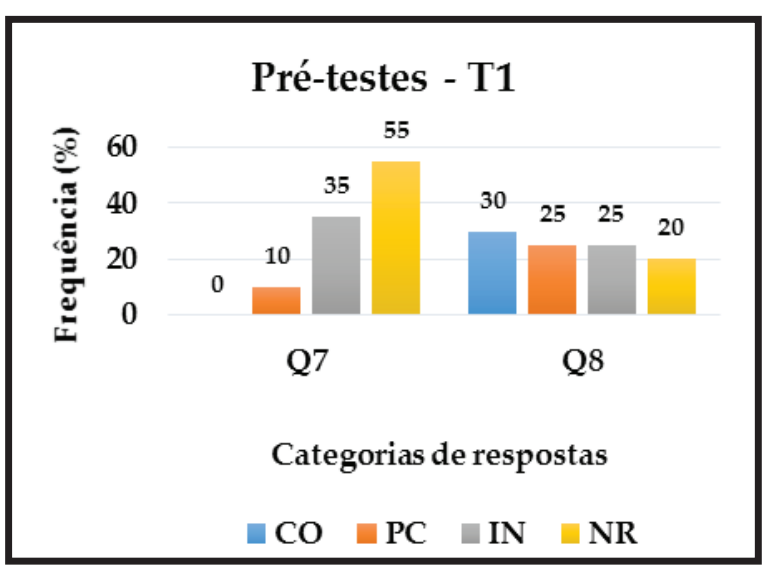

Figura 10 - Distribuição da amostra de acordo com as categorias de respostas obtidas para as 2 questões semiestuturadas (Q7 e Q8), no pré-teste (T1), onde CO = corretas; $\mathrm{PC}=$ parcialmente corretas; $\mathrm{IN}=$ incorretas; $\mathrm{NR}=$ não respondidas .

A questão 7 (Q7), que pedia a identificação das principais estruturas visíveis em um embrião de aproximadamente 5 semanas - representado pelo modelo da figura 6 - no T1 não foi respondida por $55 \%$ da amostra, porém no T3 somente $5 \%$ não responderam. Para esta questão aumentou a frequência das PC ao longo das três aplicações, porém a frequência das $\mathrm{CO}$ saiu de zero no T1, atingiu $15 \%$ no $\mathrm{T} 2$ e baixou para $10 \%$ no T3. Tal resultado surpreende um pouco, pois no modelo da figura 6 são representados primórdios de elementos macroscópicos, como os primórdios dos olhos e de outras estruturas da face e da cabeça. Uma possível explicação pode ser o fato de que tal questão solicitava a identificação de várias estruturas, algumas delas com denominações difíceis de memorizar ("arcos faríngeos", por exemplo). 


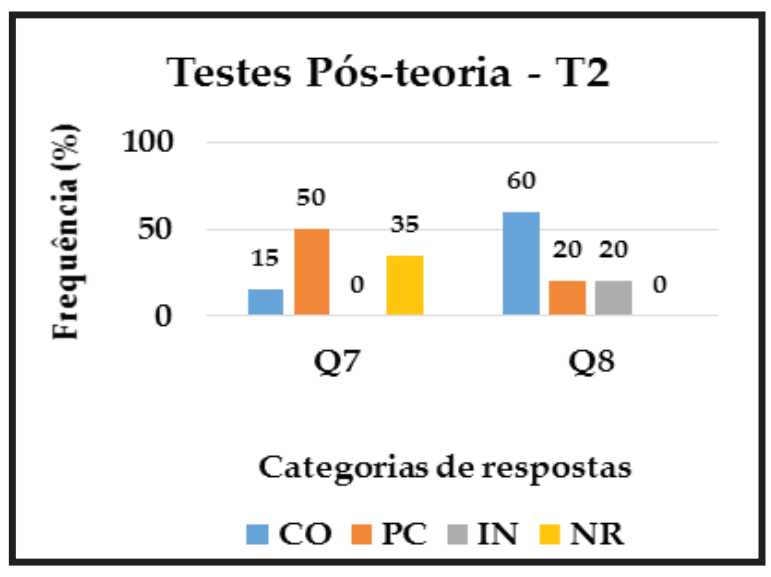

Figura 11 - Distribuição da amostra de acordo com as categorias de respostas obtidas para as 2 questões semiestuturadas (Q7 e Q8), no teste pós-teoria (T2), onde $\mathrm{CO}=$ corretas; $\mathrm{PC}=$ parcialmente corretas; $\mathrm{IN}=$ incorretas; $\mathrm{NR}=$ não respondidas.

A questão 8 (Q8) solicitava a enumeração da sequência correta em que ocorrem as fases iniciais do desenvolvimento embrionário humano. Apesar de os modelos serem estáticos, a grande maioria da amostra (90\%) acertou tal questão no teste pós-intervenção (T3). Destaca-se tal fato como muito positivo, pois considera-se mais importante o entendimento do processo de desenvolvimento do que a identificação de todas as estruturas embrionárias ou fetais ou a memorização da terminologia embriológica. Das duas questões semiestruturadas, esta foi a que apresentou maior aumento na frequência de acertos de T1 para T3.

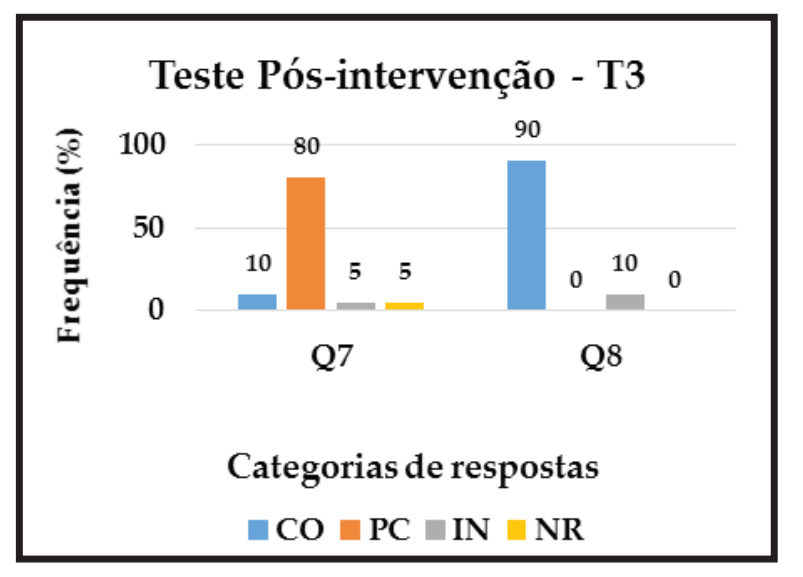

Figura 12 - Distribuição da amostra de acordo com as categorias de respostas obtidas para as 2 questões semiestuturadas (Q7 e Q8), no teste pós-intervenção (T3), onde $\mathrm{CO}=$ corretas; $\mathrm{PC}=$ parcialmente corretas; $\mathrm{IN}=$ incorretas; $\mathrm{NR}=$ não respondidas.

Na tabela 2 consta a freqüência média de acertos da amostra nas três aplicações do teste de conhecimentos.

Conforme era esperado e pode ser observado nos gráficos e na tabela 2, a frequência média de acertos
Tabela 2: Frequência média (aproximada) de acertos da amostra, onde T1 = pré-teste; T2 = teste pós-teoria; T3 = teste pós-intervenção.

\begin{tabular}{|c|c|c|}
\hline Teste & $\begin{array}{c}\text { Questões } \\
\text { fechadas } \\
\text { (\%) }\end{array}$ & $\begin{array}{c}\text { Questões } \\
\text { semiestruturadas } \\
\text { (\%) }\end{array}$ \\
\hline T1 & 44 & 15 \\
\hline T2 & 62 & 37 \\
\hline T3 & 76 & 50 \\
\hline
\end{tabular}

aumentou, consideravelmente, de $\mathrm{T} 1$ para $\mathrm{T} 3$, sendo a maior média (76\%) observada na frequência de acertos das questões fechadas no T3. Tal resultado pode ser interpretado como um avanço no processo de ensino -aprendizagem, pois indica que houve algum nível de consolidação do aprendizado. Avaliando a progressão de T2 para T3, considera-se que o método utilizado na intervenção foi "potencialmente significativo, ou seja, efetivamente voltado para favorecer a aprendizagem significativa." (LEMOS; MOREIRA, 2011, p.25).

Uma vez que os alunos amostrados, conforme relatado pelos mesmos, ainda não conheciam modelos didáticos, considera-se que a experiência aqui descrita constituiu, para tais acadêmicos, uma nova referência de alternativa metodológica para o ensino de Biologia, da qual os licenciandos poderão dispor na futura prática pedagógica. Conforme concluído por Justina; Caldeira, 2014, (p. 198), em estudo epistemológico, experienciando atividades que abordam conceitos e processos biológicos, “... os professores e pesquisadores em formação inicial estabelecem novas fronteiras de pensamento na compreensão do conhecimento biológico e o seu ensino."

\section{Conclusões}

Segundo Pedrancini et al. (2007, p. 305): “... muitas vezes, torna-se difícil perceber até que ponto está ocorrendo a aprendizagem dos conceitos e fenômenos biológicos." Entretanto, pelos dados obtidos, considera-se que a intervenção realizada teve um resultado positivo, promovendo um processo de ensino-aprendizagem mais ativo e estimulante para o aprendiz.

A análise dos testes (T1, T2 e T3), permite considerar que a intervenção promoveu, de certa forma, a continuidade do aprendizado proporcionado pelas aulas e pelas leituras feitas pela amostra.

Considera-se que as informações elucidadas pelos modelos tridimensionais interagiram com os saberes obtidos nas aulas teóricas, resultando na consolidação do aprendizado e, portanto, em uma maior apropriação de conhecimentos específicos referentes à embriogêne- 
se humana. Considera-se ainda a possibilidade de tal apropriação conduzir o aluno da aprendizagem mecânica (memorística), que deve ter ocorrido inicialmente, à aprendizagem significativa postulada por Ausubel et al. (1980).

Considerando que a amostra pesquisada foi constituída por acadêmicos de Ciências Biológicas (Licenciatura e Bacharelado), destaca-se, ainda, que a produção e/ou análise de modelos tridimensionais é importante tanto para essa formação inicial quanto para a formação continuada de professores. Segundo Axt; Moreira (1991), as universidades brasileiras devem dar importância à formação de professores para que materiais didáticos venham a ser utilizados, de forma efetiva, nas escolas.

Destaca-se, ainda, que o presente trabalho constituiu um processo de aprendizagem, especialmente no que se refere à parte metodológica e, mais especificamente, ao instrumento utilizado para a coleta de dados (teste de conhecimentos). Ao finalizar a análise de dados, constatamos que se tivéssemos incluído questões abertas no teste, poderíamos ter obtido dados mais consistentes e mais indicativos quanto à validade da intervenção realizada. Nesse sentido, pretende-se complementar esta pesquisa e dar continuidade à mesma, através da análise das respostas da amostra a questionário avaliativo da intervenção realizada.

\section{Referências}

AJAJA, O.P. Which strategy best suits biology teaching? Lecturing, concept mapping, cooperative learning or learning cycle? Electronic Journal of Science Education, v. 17, n. 1, 2013.

AMABIS, J.M.; MARTHO, G.R. (1997). Biologia das células: origem da vida, citologia, histologia, embriologia. São Paulo: Moderna. Vol. 1.

ASSMANN, A; CIPRIANI, C. R.; SILVA, J.C.; ROCHA, R. T.; SCHATE, JJ.C.; CARVALHO, M.S.L; NAZARI, E.M.; MÜLLER, Y.M.R. A embriologia humana e a extensão universitária. Extensio, Florianópolis, UFSC, v.1, n.0, 2004.

AUSUBEL, D.P., NOVAK, J. e HANESIAN, H. Psicologia educacional. Rio de Janeiro: Editora Interamericana Ltda, 1980.

AVERSI-FERREIRA, T.A.; AVERSI-FERREIRA, R.A.G.M.F.; NASCIMENTO, G.N.L.; NYAMDAVAA, N.; ARAUJO, M.F.; RIBEIRO, P.P.; DA SILVA, N.C.; BRANDÃO, L.D.; GRATÃO, L.H.A.; ABREU, T; PFRIMER, G.A.; SOUZA, V.V.; SOARES, N.P.; HORI, E.; NISHIJO, H. Teaching Embryology Using Models Construction in Practical Classes. International Journal of Morphology, v. 30, n. 1, p. 188-195, 2012.
AVERSI-FERREIRA, T.A.; MONTEIRO, C.A.; MAIA, F.A.; GUIMARÃES, A.P.R.; CRUZ, M.R. Estudo de neurofisiologia associado com modelos tridimensionais construídos durante o aprendizado. Bioscience Journal, Uberlândia, v. 24, n. 1, p. 98-103, jan/mar/2008.

AXT, R.; MOREIRA, M.A. O ensino experimental e a questão do equipamento de baixo custo. Revista de Ensino de Física, v. 13, dez/1991, p. 97-103.

BRASIL, Ministério da Educação Biologia: catálogo do Programa Nacional do Livro Didático para o Ensino Médio - 2009. Secretaria de Educação Básica - Fundo Nacional de Desenvolvimento da Educação. Brasília: MEC, 2008. Disponível em: <http://www.fnde.gov.br/ programas/livro-didatico/guia-do-livro/item/3812guia-pnlem-2009>.

DEPARTAMENTO DE MORFOLOGIA/Unifesp. Disponível em: <http://www.unifesp.br/dmorfo/ histologia/ensino/ovario/histologia.htm>. Acesso em: 25 jun. 2014.

FREITAS L. A. M. de; BARROSO H. F. D.; RODRIGUES H. R.; AVERSI-FERREIRA T. A. Construção de modelos embriológicos com material reciclável para uso didático. Bioscience Jornal, Uberlândia, v. 24, n. 1, p. $91-97,2008$.

GIL, Antonio Carlos. Métodos e Técnicas de Pesquisa Social, 5. ed. São Paulo: Atlas, 2006.

GILBERT, J.K. Models and Modelling: Routes to More Authentic Science Education. International Journal of Science and Mathematics Education, v. 2, n. 2, p. 115-130, 2004.

GILBERT, S.F. Biologia do desenvolvimento. Ribeirão Preto: Sociedade Brasileira de Genética, 1995.

GUIMARÃES, E. M.; FERREIRA, L. B. M. O uso de modelos na formação de professores de ciências. In: $2^{\text {o }}$ Encontro Regional Sul de Ensino de Biologia e $3^{\underline{a}}$ Jornada de Licenciatura em Ciências Biológicas da UFSC. Florianópolis, UFSC, 2006.

JUSTI, R.; VAN DRIEL, J. The use of the Interconnected Model of Teacher Professional Growth for understanding the development of science of teachers' knowledge on models and modelling. Teaching and Teacher Education, v.22, p.437-450, 2006.

JUSTINA L. D. A; FERLA M. R. A utilização de modelos didáticos no ensino de Genética - exemplo de representação de compactação do DNA eucarioto. Arquivos do Mudi, Maringá, v. 10, n. 2, p. 35-40, 2006. 
JUSTINA, L.A.D; CALDEIRA, A.M.A. Uma investigação com graduandos da licenciatura em Ciências Biológicas sobre a relação genótipo-fenótipo na perspectiva da epistemologia de Gaston Bachelard. Revista Electrónica de Enseñanza de las Ciencias, v. 13, n. 2, p. 179-200, 2014.

LEMOS, E.S.; MOREIRA, M.A. A avaliação da aprendizagem significativa em Biologia: um exemplo com a disciplina Embriologia. Aprendizagem Significativa em Revista/Meaningful Learning Review, v.1, n.2, p. 15-26, 2011.

LOPES, S. (2006). Bio. São Paulo: Saraiva. Vol. Único.

MEIRA, M.S. Construção de modelo didático tridimensional para estudo da estrutura óssea microscópica - relato de experiência com graduandos das ciências naturais e da saúde. Anais do XVIII SEMINÁRIO INTERNACIONAL DE EDUCAÇÃO, Cachoeira do Sul, 2013. Disponível em: <http://www.sieduca.com.br/?principal=lista trabalhos\&eixo=1\&modalidade $=2>$. Acesso em: 21 jan. 2014.

MOREIRA, M. A. Mapas conceituais, Diagramas V e Organizadores Prévios. In: Conjunto de artigos sobre possíveis estratégias facilitadoras da aprendizagem significativa com o objetivo de subsidiar didaticamente o professor pesquisador, em particular da área de ciências. $1^{\underline{a}}$ edição. Porto Alegre, Brasil, Instituto de Física, UFRGS, 2009. Disponível em: <http://www. if.ufrgs.br/ moreira/Subsidios3.pdf $>$. Acesso em 10 mar. 2012.

MOORE, K.L; PERSAUD, V.T.N. Embriologia Clínica. Rio de Janeiro: Editora Guanabara Koogan, 2000. 543p.

. Embriologia Clínica. Rio de Janeiro: Elsevier, 2004. 609p. (tradução de: The developing human, 7 th ed).

Embriologia Clínica. 8.ed. Rio de Janeiro: Editora Guanabara Koogan, 2008. 536p.

MOORE, K.L.; PERSAUD, T.V.N.; TORCHIA, M.G. Before we are born: essentials of Embryology and Birth Defects. Canadá: Elsevier, 2013, 348p.

NASCIMENTO, A. M. B. T.; SIQUEIRA, A.K. L.; SILVA, M. M. F. M.; DIONÍZIO, S. C. Aplicação de modelos didáticos sobre o animal invertebrado tênia no ensino de Biologia integrado ao PIBID. III ENCONTRO NACIONAL DE ENSINO DE CIÊNCIAS DA SAÚDE E DO AMBIENTE, NITERÓI-RJ, 2012. Anais... Disponível em:http://www.ensinosaudeambiente. com.br/eneciencias/anaisiiieneciencias/trabalhos/T91. pdf>. Acesso em: 13 jan. 2013.

OLIVEIRA, M.S.; KERBAUY, M.N.; FERREIRA, C.N.M.; SCHIAVÃO, L.J.V.; ANDRADE, R.F.A.A.; SPADELLA, M.A. Uso de material didático sobre Embriologia do Sistema Nervoso: avaliação dos estudantes. Revista Brasileira de Educação Médica, v. 36, n.1, p.83-92, 2012.

PEDRANCINI, V. D.; CORAZZA-NUNES, M. J.; GALUCH, M. T. B.; MOREIRA, A. L. O. R.; RIBEIRO, A. C. Ensino e aprendizagem em biologia do ensino médio e a apropriação do saber científico e biotecnológico. Revista Electrónica Enseñanza de las Ciencias, v. 6, n.2, p. 299-309, 2007.

PEROTTA, B.; FIEDLER, P. T.; SANTOS, S. H. P. D.; HIROSE, T. E.; RODRIGUES, A. L. D. M.; OLIVEIRA, S. A. D.; SATO, M. H.; ÁVILA, H. S.; MORAES, T. C. D.; FERREIRA, F.D.F. Demonstração prática do desenvolvimento pulmonar humano. Arquivos da Apadec, Maringá, v. 8, supl. 2, p. 14, out. 2004.

RIBEIRO, M.G. Inclusão sócio-educacional no ensino de ciências integra alunos e coloca a célula ao alcance da mão. In: ENCONTRO DE EXTENSÃO DA UNIVERSIDADE FEDERAL DE MINAS GERAIS, 7, 2004, Belo Horizonte. Anais... $7^{\circ}$ Encontro de Extensão da UFMG, 2004. p. 1-8.

RODRIGUES, A.L.M., FIELER, P.T., SAMPS, S.H.P.D., PEROTTA, B., HIROSE, T.E., OLIVERIA, S.A.D., SATO, M.H., ÁVILA, H.S., MORAES, T.C.D.; FERREIRA, F.D.F.I. Embriologia prática - uma lição diferente. Arquivos da Apadec, 8, 2, 11, 2004.

ROHEN, J.W.; LÜTJEN-DRECOLL, E. Embriologia funcional: o desenvolvimento dos sistemas funcionais do organismo humano. Rio de Janeiro: Guanabara Koogan, 2005.

SADLER, T.W. Langman's Medical Embryology. Baltimore, Maryland: Williams \& Wilkins, 1995. 460p.

. Langman: Embriologia Médica. 9.ed. Rio de Janeiro: Guanabara Koogan, 2005. 347p.

SEPEL, L. M. N.; LORETO, E. L. S. Relação entre membrana plasmática e citoesqueleto na forma celular: um estudo com modelos. Revista Brasileira de Ensino de Bioquímica e Biologia Molecular, v. 1, p. 1-6, 2003.

. Estrutura do DNA em origami - possibilidades didáticas. Genética na Escola - SBG, Ribeirão Preto, 02.01, p.3 - 5, 2007.

SETÚVAL, F.A.R.; BEJARANO, N.R.R. Os modelos didáticos com conteúdos de Genética e a sua 
importância na formação inicial de professores para o ensino de Ciências e Biologia. In: VII Enpec ENCONTRO NACIONAL DE PESQUISA EM ENSINO DE CIÊNCIAS, Florianópolis, 2009. Anais... Disponível em: <http://posgrad.fae.ufmg.br/posgrad/viienpec/ pdfs/1751.pdf>. Acesso em: 24 abr. 2012.

SHIOTA, K. Advances in Study of Fetal Development: From Descriptive to Dynamic Embryology. 2012. Donald School Journal $\mathrm{f}$ Ultrasound in Obstetrics and Gynecology, v. 6, n. 2, p. 171-178, 2012.

SOUSA, G.; FEITOZA, E.; PAZ, G. O uso de modelos na abordagem de isomeria de compostos de coordenação. 11ํㅗimpósio Brasileiro de Educação Química, Teresina/ PI, 2013. Anais... Disponível em: <http://www.abq. org.br/simpequi/2013/trabalhos/2247-16286.html>. Acesso em: 20/maio/2014.

TEMP, D. S.; CARPILOVSKY, C. K.; GUERRA, L. Cromossomos, gene e DNA: utilização de modelo didático. Genética na Escola, p. 9-11, 2011.

TRIVIÑOS, A.N.S. Introdução à pesquisa em ciências sociais: a pesquisa qualitativa em educação. São Paulo: Atlas, 2008.

WESTPHAL, M.; PINHEIRO, T.C. A epistemologia de Mario Bunge e sua contribuição para o ensino de Ciências. Ciência \& Educação, v.10, n.3, p. 585-596.

YAMADA, S.; UWABE, C.; NAKATSU-KOMATSU, T.; MINEKURA, Y.; IWAKURA, M.; MOTOKI, T.; NISHIMIYA, K.; IIYAMA, M.; KAKUSHO, K.; MINOH, M.; MIZUTA, S.; MATSUDA, T.; MATSUDA, Y.; HAISHI, T.; KOSE, K.; FUJII, S.; SHIOTA, K. Graphic and movie llustration of human prenatal development and their application to embryological education based on the human embryo specimens in the Kyoto Collection. Developmental Dynamics, v. 235, n.2, p. 468-477, 2006. Disponível em: <http://onlinelibrary. wiley.com/doi/10.1002/dvdy.20647/pdf > Acesso em: 25 abr. 2013. 